\title{
Racial and Ethnic Disparities in Patient Experiences in the United States: 4-Year Content Analysis of Twitter
}

Yulin Hswen ${ }^{1,2,3,4}$, ScD; Jared B Hawkins ${ }^{4,5}$, MMSc, PhD; Kara Sewalk ${ }^{4}$, MPH; Gaurav Tuli ${ }^{4}$, PhD; David R Williams ${ }^{6,7}$, MPH, PhD; K Viswanath ${ }^{6,8}$, PhD; S V Subramanian ${ }^{6,7}, \mathrm{PhD}$; John S Brownstein ${ }^{4,5}, \mathrm{PhD}$

\footnotetext{
${ }^{1}$ Boston Children's Hospital, Boston, MA, United States

${ }^{2}$ Department of Epidemiology and Biostatistics, University of California San Francisco, San Francisco, CA, United States

${ }^{3}$ Bakar Computational Health Sciences Institute, University of California San Francisco, San Francisco, CA, United States

${ }^{4}$ Innovation Program, Boston Children's Hospital, Boston, MA, United States

${ }^{5}$ Computational Epidemiology Lab, Harvard Medical School, Boston, MA, United States

${ }^{6}$ Department of Social and Behavioral Sciences, Harvard TH Chan School of Public Health, Boston, MA, United States

${ }^{7}$ Harvard Center for Population and Development Studies, Harvard University, Cambridge, MA, United States

${ }^{8}$ Center for Community-Based Research, Dana-Farber Cancer Institute, Boston, MA, United States
}

\section{Corresponding Author:}

Yulin Hswen, ScD

Department of Epidemiology and Biostatistics

University of California San Francisco

550 16th Street

San Francisco, CA

United States

Phone: 16177751889

Email: yhswen@gmail.com

\section{Abstract}

Background: Racial and ethnic minority groups often face worse patient experiences compared with the general population, which is directly related to poorer health outcomes within these minority populations. Evaluation of patient experience among racial and ethnic minority groups has been difficult due to lack of representation in traditional health care surveys.

Objective: This study aims to assess the feasibility of Twitter for identifying racial and ethnic disparities in patient experience across the United States from 2013 to 2016.

Methods: In total, 851,973 patient experience tweets with geographic location information from the United States were collected from 2013 to 2016. Patient experience tweets included discussions related to care received in a hospital, urgent care, or any other health institution. Ordinary least squares multiple regression was used to model patient experience sentiment and racial and ethnic groups over the 2013 to 2016 period and in relation to the implementation of the Patient Protection and Affordable Care Act (ACA) in 2014.

Results: Racial and ethnic distribution of users on Twitter was highly correlated with population estimates from the United States Census Bureau's 5-year survey from $2016\left(r^{2}=0.99 ; P<.001\right)$. From 2013 to 2016, the average patient experience sentiment was highest for White patients, followed by Asian/Pacific Islander, Hispanic/Latino, and American Indian/Alaska Native patients. A reduction in negative patient experience sentiment on Twitter for all racial and ethnic groups was seen from 2013 to 2016. Twitter users who identified as Hispanic/Latino showed the greatest improvement in patient experience, with a 1.5 times greater increase $(P<.001)$ than Twitter users who identified as White. Twitter users who identified as Black had the highest increase in patient experience postimplementation of the ACA (2014-2016) compared with preimplementation of the ACA (2013), and this change was 2.2 times $(P<.001)$ greater than Twitter users who identified as White.

Conclusions: The ACA mandated the implementation of the measurement of patient experience of care delivery. Considering that quality assessment of care is required, Twitter may offer the ability to monitor patient experiences across diverse racial and ethnic groups and inform the evaluation of health policies like the ACA.

(J Med Internet Res 2020;22(8):e17048) doi: 10.2196/17048 


\section{KEYWORDS}

racial disparities; race; patient experience; policy; social media; digital epidemiology; social determinants of health; health disparities; health inequities

\section{Introduction}

In the United States, racial and ethnic minority populations experience suboptimal access to quality health care [1]. Since patient experience is strongly associated with quality health care [2-4], lower quality health care within these groups may be attributed to poorer patient experiences. Because of these poorer experiences by racial and ethnic minorities, authentic patient experience can be difficult to capture in traditional health care research. For instance, a systematic review of 44 articles showed that mistrust, stigmatization, fears, and lack of access to information prevented racial and ethnic minority groups from participating in health research [5].

Most research surrounding patient experience has been conducted by the health care system, whereby quality assessments about patient experience are retrieved from the health care institution that is providing these health care services to the patients [1,6-8]. Therefore, fear of consequences of reporting negative feedback to the health care institution that is responsible for respondents' care may bias the results of these studies [9-11]. The validity of health care-based surveys about patient experience are put into question because a strong correlation between positive patient satisfaction and response rate has been documented [12-14]. Research suggests that levels of reported patient satisfaction with health care may be inflated due to high risks of response bias, especially among racial and ethnic minorities who have historically received poor treatment and care [13]. For example, White patients are more likely to respond to health care surveys compared with racial and ethnic minorities $[15,16]$ and are overrepresented in many health care studies about patient experience and care [17].

Measurement of patient experience has also gained recognition as a component of the Patient Protection and Affordable Care Act (ACA) of 2010 [18]. The ACA was enacted in order to improve the access to health care through the expansion of public health coverage, improve affordability of health insurance, and make the health care system more accountable to diverse patient populations, like racial and ethnic minorities that have historically had a lack of health coverage [19]. Since the ACA's major provisions came into force in 2014, as of 2016, it is estimated that up to 24 million additional people have received insurance coverage [20]. Additionally, the law repeatedly refers to the importance of patient-centeredness, patient satisfaction, and the measurement of patient experience of care, highlighting the importance of accurately measuring these patient-reported experiences [21,22]. Therefore, novel approaches are needed to better understand patient experience, especially among underrepresented racial and ethnic minority groups, which could also shed light on the impact of new health care policies and changing legislation, such as the implementation of the ACA.

Data derived from Twitter may offer an opportunity to capture authentic patient experiences and broaden the view of existing health care surveys on patient satisfaction. Twitter is a popular social networking and microblogging service that has over 330 million monthly active users worldwide and approximately 500 million tweets per day $[23,24]$. Tweets are limited to 280 characters and have been recognized as a source of organic sentiment and opinions [25]. The Twitter platform has been widely recognized as a source to monitor public sentiment across a spectrum of health-related issues, including mental health [26-28], vaccination [29], and smoking [30]. Most recently, Twitter has emerged as a potential source of information for capturing hospital and health care experiences of sexual minorities [31,32]. Considering that a greater proportion of Black and Hispanic users are on Twitter [33,34], data collected from this social media platform may make it possible to capture patient experiences from minority populations that are typically underrepresented in traditional research on patient satisfaction.

This study seeks to evaluate the ability of Twitter to monitor patient experiences in racial and ethnic minority groups in the United States. Specifically, we examined tweets about patient experience among racial and ethnic groups, including White, Black, Hispanic/Latino, Asian/Pacific Islander, and American Indian/Alaska Native patients in the United States. We further investigated trends in sentiment of these tweets across race and ethnicity from 2013 to 2016 . Lastly, we explored changes in patient experience sentiment postimplementation of the ACA (2014-2016) to preimplementation of the ACA (2013) across racial and ethnic groups to understand the potential impact of this health policy on racial and ethnic disparities in patient experience.

\section{Methods}

\section{Patient Experience Data Set}

This study used a previously established Twitter patient experience data set to investigate racial and ethnic disparities in patient experience in the United States [35]. This patient experience data set was created from a support vector machine-based supervised machine learning classifier that was iteratively built to specifically identify tweets related to patient experience. A patient experience tweet was defined as any tweet that discussed any exposure to health care, such as care received in a hospital, urgent care, or any other health institution.

We used a geolocation inference engine validated by a previous study for the patient experience data set [35] that used a combination of users' profiles, GPS, and the Google Maps Geocoding application programming interface to identify the geographic location of the user. A total of 2,759,257 tweets were labeled as patient experience tweets from February 1, 2013, to February 28, 2017, out of which 876,384 (31.76\%) tweets were inferred to one of the 50 US states, the District of Columbia, or the US Virgin Islands by the geolocation inference engine [35]. To align our analyses with the 2016 census data, we excluded data from 2017. In total, 851,973 geolocation inference tweets were used in this analysis. 


\section{Patient Experience Sentiment}

We used natural language processing to measure the sentiment of all patient experience tweets. The sentiment of patient experience tweets was determined using a widely accepted lexicon and rule-based sentiment classifier for microblogs, Valence Aware Dictionary for Sentiment Reasoner (VADER). VADER is based on a pattern library that is trained from human-annotated words commonly found in product reviews [36,37]. VADER is often used for product reviews and news articles and therefore does not always contain similar text-based characteristics to Twitter. Therefore, we appended VADER's dictionary and rules to provide broader representation for Twitter, such as incorporating over 110 emojis and their respective sentiment scores [38]. VADER computes sentiment for each word and generates a compound score for the sentence by summing the sentiment score of each word. We considered sentiment score to be positive if the mean compound score was greater than or equal to 0.3 and negative if the score was less than or equal to -0.3 . Mean compound scores between -0.3 and 0.3 were considered neutral.

\section{Classification of Race and Ethnicity}

The relationship between surname distribution and population structure dates to the 19 th century $[39,40]$. More recently, the Human Genome Diversity Project has shown a strong correlation of surnames and genetic linkages between human groups [41], which has caused name-based classification of race and ethnicity to be frequently used in population-based studies to identify racial and ethnic identities when information is not directly available [39]. In 2010, the United States Census Bureau conducted a study to develop a classification system to identify racial and ethnic identities associated with a list of names from the 2010 decennial survey [42]. In this study, surnames were recorded for 295 million people (95.5\% of the population) and surnames with a frequency of 100 or more were used to identify race and ethnicity. These 162,253 names cover $90 \%$ of the people recorded in the United States Census Bureau decennial survey in 2010 .

Therefore, we used the United States Census Bureau surname classification system [43] to build a surname classifier to identify race and ethnicity in our Twitter population. The profile names of Twitter users were collected and matched to the United States Census Bureau surname classification database $(\mathrm{N}=162,253)$ to identify the race and ethnicity of Twitter users in our study [42]. Racial and ethnic categorizations were based on the categories used in the United States Census Bureau 2010 decennial survey, which included White, Black, Hispanic/Latino, Asian/Pacific Islander, and American Indian/Alaska Native persons. Out of the 851,973 geolocation tweets, 392,215 tweets were used that had racial and ethnic inferred information in the analyses presented in this study.

\section{Statistical Analysis}

We used two methods to compare the racial and ethnic distribution of our Twitter data with the 5-year US census estimates for 2016. We first used the Kendall $\tau$ rank correlation to compare the ranking of the states by number of users that tweeted about patient experience and compared this with the rank of populations by state based on United States Census Bureau's 2016 American Community Survey 5-year estimates. Second, we quantified the strength of the correlation of distribution across race and ethnicity for each state with a Pearson correlation test and reported the $r^{2}$ coefficient variable.

We identified the relative difference in sentiment of patient experience across race and ethnicity using ordinary least squares regression. To examine the change in sentiment in patient experience across race and ethnicity from 2013 to 2016, we included a year $\times$ race/ethnicity interaction term and tested its significance in the ordinary least squares regression model. To evaluate the potential impact of the implementation of the ACA's full provisions in 2014, we generated a dichotomous dummy variable to distinguish between the two time periods of preimplementation (2013) versus postimplementation of the ACA's provisions (2014-2016), along with the interaction terms between that variable and the variable of race and ethnicity. This study received approval from the Boston Children Hospital's Institutional Review Board.

\section{Results}

\section{Geographic Distribution of Patient Experience Across Race and Ethnicity}

The results between the distribution of Twitter users per state and the population estimates from the 2016 census 5-year survey show that Kendall $\tau$ was $0.845(P<.001)$ and Pearson coefficient $r^{2}$ was $0.99(P<.001)$, as illustrated in Figure 1. The Kendall $\tau$ rank correlation was highest for the distribution of Hispanic/Latino patients (tau- $b=0.74$ ), followed by Black (tau-b=0.62), White (tau-b=0.57), Asian/Pacific Islander (tau-b=0.47), and lastly American Indian/Alaska Native patients (tau-b=0.40), with all $P$ values $<.001$. The Pearson $r^{2}$ coefficient for the correlation between the patient experience user counts per state and the corresponding population estimates by the US census was highest for Hispanic/Latino patients $\left(r^{2}=0.98\right)$, followed by Asian/Pacific Islander $\left(r^{2}=0.91\right)$, White $\left(r^{2}=0.85\right)$, Black $\left(r^{2}=0.91\right)$, and lastly American Indian/Alaska Native patients $\left(r^{2}=0.59\right)$, with all $P$ values $<.001$, as seen in Figure 2. 
Figure 1. Correlation between the patient experience user counts per state and the corresponding population estimates by US census. PTE: patient experience.

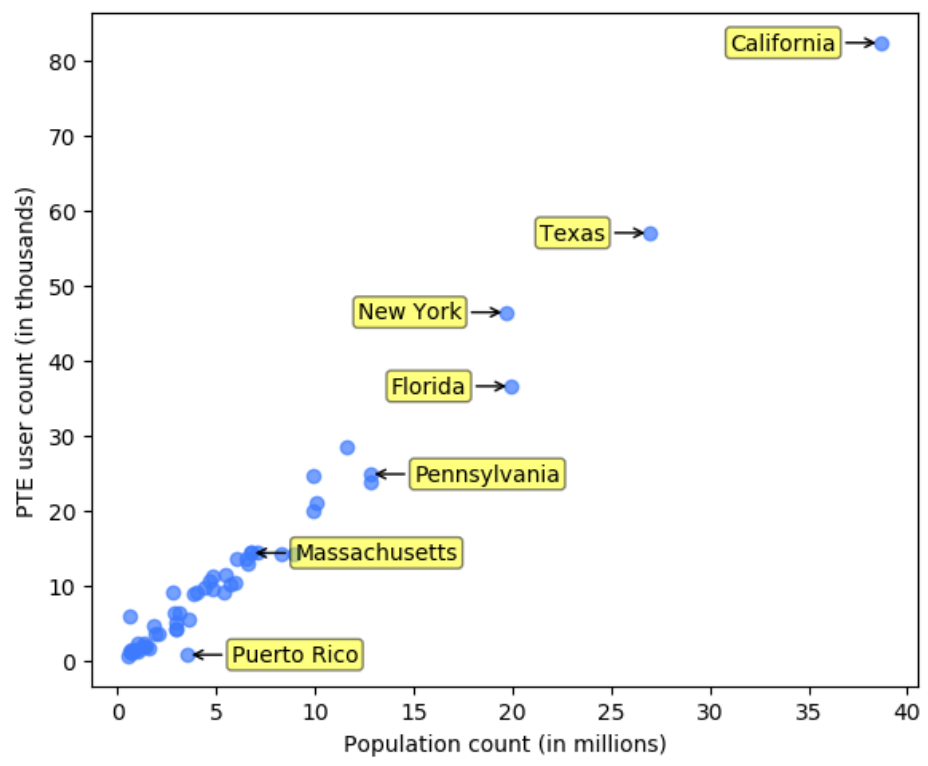

Figure 2. Correlation between the patient experience user counts per state and the corresponding population estimates by the US census by racial and ethnic group from 2013 to 2016.
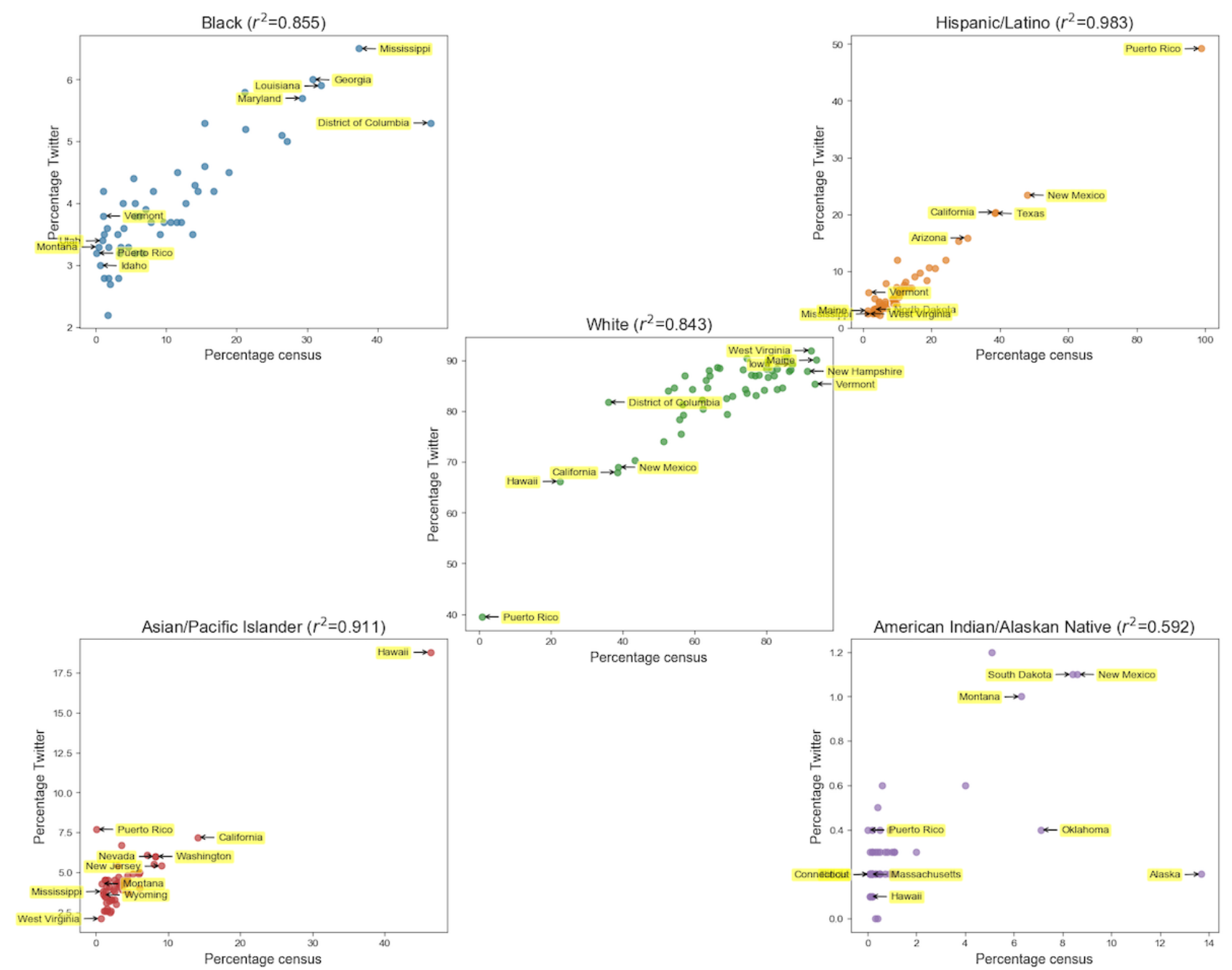


\section{Patient Experience Sentiment Across Race and Ethnicity From 2013 to 2016}

Table 1 shows the descriptive statistics of the mean, median, and standard deviation across each racial and ethnic group for each year and the overall average. The overall mean sentiment from 2013 to 2016 was highest for White patients, followed by Black, Asian/Pacific Islander, Hispanic/Latino, and lastly American Indian/Alaska Native patients, as shown graphically in Figure 3. Baseline patient experience sentiment in 2013 was the highest for White patients, followed by Black, Asian/Pacific
Islander, Hispanic/Latino, and then American Indian/Alaska Native patients. In 2014, the patient experience sentiment was the highest for Black patients, followed by White, Hispanic/Latino, Asian/Pacific Islander, and then American Indian/Alaska Native patients. In 2015, the patient experience sentiment was the highest for White patients, followed by Black, Hispanic/Latino, Asian/Pacific Islander, and then American Indian/Alaska Native patients. Lastly, in 2016 the patient experience sentiment was the highest for White patients, followed by Black, Asian/Pacific Islander, Hispanic/Latino, and then American Indian/Alaska Native patients.

Table 1. Patient experience sentiment raw scores by racial and ethnic group from 2013 to 2016.

\begin{tabular}{|c|c|c|}
\hline Race and year & Tweets, $\mathrm{n}$ & Sentiment, mean (SD) \\
\hline \multicolumn{3}{|l|}{ White } \\
\hline 2013 & 109,656 & $-0.043(0.478)$ \\
\hline 2014 & 89,540 & $-0.018(0.478)$ \\
\hline 2015 & 63,459 & $-0.004(0.480)$ \\
\hline \multicolumn{3}{|l|}{ Black } \\
\hline 2013 & 5552 & $-0.087(0.478)$ \\
\hline 2014 & 5121 & $0.004(0.489)$ \\
\hline 2015 & 3216 & $-0.036(0.484)$ \\
\hline \multicolumn{3}{|c|}{ Hispanic/Latino } \\
\hline 2013 & 12,825 & $-0.094(0.487)$ \\
\hline 2014 & 9495 & $-0.069(0.491)$ \\
\hline 2015 & 6254 & $-0.037(0.490)$ \\
\hline 2016 & 5654 & $-0.038(0.492)$ \\
\hline \multicolumn{3}{|c|}{ Asian/Pacific Islander } \\
\hline 2013 & 5734 & $-0.092(0.478)$ \\
\hline 2014 & 4797 & $-0.059(0.480)$ \\
\hline 2015 & 3949 & $-0.056(0.500)$ \\
\hline 2013 & 310 & $-0.154(0.456)$ \\
\hline 2014 & 304 & $-0.085(0.477)$ \\
\hline 2015 & 258 & $-0.078(0.465)$ \\
\hline 2016 & 238 & $-0.034(0.485)$ \\
\hline
\end{tabular}


Figure 3. Average patient sentiment by racial and ethnic group from 2013 to 2016 .

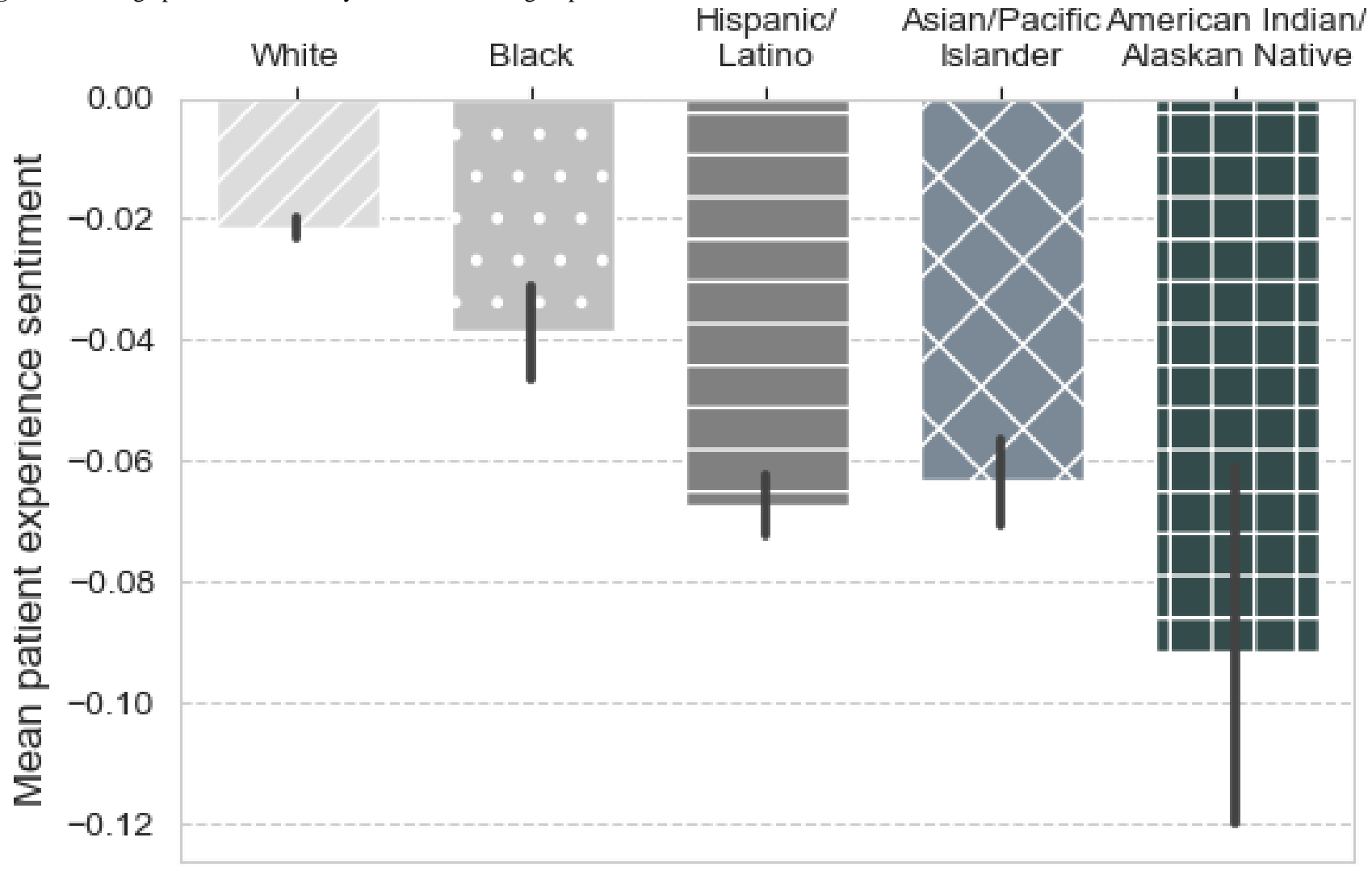

The linear regression model using race as the predictor variable is shown in Table 2. Compared with White patients, other racial and ethnic groups had statistically significant lower patient experience sentiments. American Indian/Alaska Native patients had the lowest patient experience sentiment, with a patient experience sentiment score that was 0.070 points less than White patients $(P<.001)$. This was followed by Hispanic/Latino patients, with 0.046 fewer patient experience sentiment points $(P<.001)$, then Asian/Pacific Islander patients, who had 0.042 fewer patient experience sentiment points $(P<.001)$, and then Black patients, with 0.017 fewer patient experience sentiment points than White patients $(P<.001)$. A graph of the average patient experience sentiment by race from 2013 to 2016 is depicted in Figure 3. 
Table 2. Ordinary least squares modeling effects of year and racial and ethnic group on patient experience sentiment.

\begin{tabular}{|c|c|c|c|c|c|c|}
\hline \multirow[t]{2}{*}{ Predictor variables } & \multicolumn{2}{|c|}{ Model 1: combined years } & \multicolumn{2}{|c|}{ Model 2: yearly change } & \multicolumn{2}{|c|}{ Model 3: pre-post $\mathrm{ACA}^{\mathrm{a}, \mathrm{b}}$} \\
\hline & Coefficient & $P$ value & Coefficient & $P$ value & Coefficient & $P$ value \\
\hline \multicolumn{7}{|l|}{ Race } \\
\hline White & $-0.0215^{\mathrm{c}}$ & $<.001$ & $-28.21^{\mathrm{c}}$ & $<.001$ & $-\mathrm{d}$ & - \\
\hline Black & -0.0171 & $<.001$ & -9.08 & .20 & - & - \\
\hline Hispanic/Latino & -0.0460 & $<.001$ & -14.19 & .01 & - & - \\
\hline Asian/Pacific Islander & -0.0419 & $<.001$ & -8.77 & .18 & - & - \\
\hline American Indian/Alaska Native & -0.0702 & $<.001$ & -46.71 & .08 & - & - \\
\hline \multicolumn{7}{|l|}{ Change over years 2013-2016 } \\
\hline \multicolumn{7}{|l|}{ Race } \\
\hline White & - & - & $0.014^{\mathrm{c}}$ & $<.001$ & - & - \\
\hline Black & - & - & 0.0045 & .21 & - & - \\
\hline Hispanic/Latino & - & - & 0.0070 & .01 & - & - \\
\hline Asian/Pacific Islander & - & - & 0.0043 & .19 & - & - \\
\hline American Indian/Alaska Native & - & - & 0.0232 & .08 & - & - \\
\hline \multicolumn{7}{|l|}{ Baseline Pre-ACA (2013) } \\
\hline \multicolumn{7}{|l|}{ Race } \\
\hline White & - & - & - & - & $-0.0433^{\mathrm{c}}$ & $<.001$ \\
\hline Black & - & - & - & - & -0.0433 & $<.001$ \\
\hline Hispanic/Latino & - & - & - & - & -0.0487 & $<.001$ \\
\hline Asian/Pacific Islander & - & - & - & - & -0.0511 & $<.001$ \\
\hline American Indian/Alaska Native & - & - & - & - & -0.1112 & $<.001$ \\
\hline \multicolumn{7}{|l|}{ Change Post-ACA (2014-2017) } \\
\hline \multicolumn{7}{|l|}{ Race } \\
\hline White & - & - & - & - & $0.033^{\mathrm{c}}$ & $<.001$ \\
\hline Black & - & - & - & - & 0.0388 & $<.001$ \\
\hline Hispanic/Latino & - & - & - & - & 0.0086 & .28 \\
\hline Asian/Pacific Islander & - & - & - & - & 0.0098 & .08 \\
\hline American Indian/Alaska Native & - & - & - & - & 0.0540 & .09 \\
\hline
\end{tabular}

${ }^{\mathrm{a}}$ ACA: Affordable Care Act.

${ }^{\mathrm{b}}$ Change from preimplementation to postimplementation of the ACA.

${ }^{\mathrm{c}}$ Reference category.

${ }^{\mathrm{d}}$ Not applicable.

\section{Changes in Patient Experience Sentiment Across Race and Ethnicity}

The changes in slope for patient experience sentiment across each racial and ethnic group are shown in regression model 2 in Table 2 and visually displayed in Figure 4. The largest increase in mean sentiment for all racial and ethnic groups was seen from 2013 to 2014, and mean sentiment continued to increase in 2015 and 2016, as illustrated in Figure 4. The ordinary squares regression model 2 showed that the yearly increase in patient experience sentiment was 0.014 points $(P<.001)$, and for Hispanic/Latino patients it was 0.021 $(P<.001)$. For Black patients, it was 0.0185 points $(P=.21)$, for Asian/Pacific Islander patients it was $0.0183(P=.19)$, and for American Indian/Alaska Native patients the yearly increase was $0.037(P=.08)$. 
Figure 4. Overall average patient experience sentiment by racial and ethnic group for the years from 2013 to 2016.

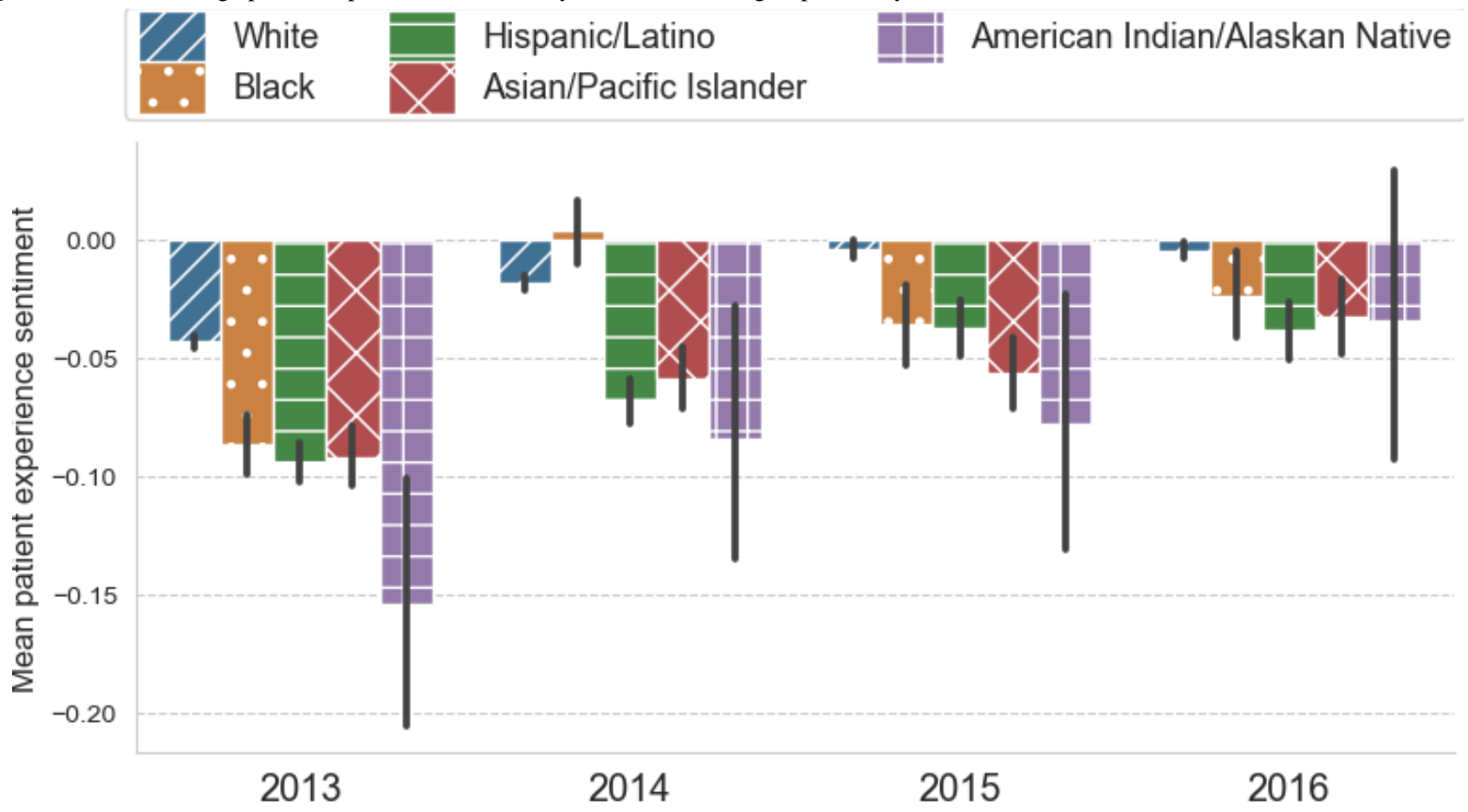

Patient experience increased in all racial and ethnic groups postimplementation of the ACA's full provisions (2014-2016) compared with preimplementation of the ACA (2013), which is shown in regression model 3 in Table 2. Twitter users who identified as Black experienced a 0.0718-point $(P<.001)$ change in patient experience sentiment when comparing preimplementation and postimplementation of the ACA's full provisions. Twitter users who identified as White experienced a 0.0330 -point $(P<.001)$ change in patient experience sentiment from preimplementation to postimplementation of the ACA's full provisions.

\section{Discussion}

\section{Monitoring Patient Experience Sentiment of Racial and Ethnic Minority Groups Using Twitter}

This study used a machine learning classifier on patient experience with data captured from Twitter to measure changes in patient experience sentiment in the United States across racial and ethnic groups. Over 2.8 million tweets about patient experience were collected and a strong correlation between the distribution of users by race and ethnicity per state and the corresponding population estimates by the US census was seen. These findings showcase a promising approach for using Twitter to capture patient health care experiences of minority racial and ethnic groups. We were also able to compare patient experiences across racial and ethnic groups and found similar disparities in patient experience that have been shown in previous patient satisfaction surveys $[44,45]$. Twitter users who identified as White tweeted more positively about their health care experiences compared with all other racial and ethnic groups in our study. The Hospital Consumer Assessment of Healthcare Providers and Systems, a survey overseen by the Agency for Healthcare Research and Quality that asks patients to report their health care experiences, has yielded similar results, with
non-Hispanic White patients reporting better experiences compared with all other racial and ethnic groups [7]. However, this same survey found that Asian patients reported the worst disparities in hospital experiences compared with White patients [7].

There is a large absence of data from American Indian/Alaska Native patients about their experiences with health care [46]. The limited studies on American Indian/Alaska Native patients have shown that they report high levels of discrimination [47], mistrust, and low satisfaction [46]. Additionally, American Indian/Alaska Native patients have the highest health burden of illness, injury, and premature mortality [48-50]. Results from our study suggest that Twitter users who identified as American Indian/Alaska Native tweeted most negatively about their patient experience, which appears consistent with existing findings. This also indicates that Twitter may be a valuable source to capture information about this vulnerable patient group that is often difficult to capture in traditional surveys [46].

Fear about the consequences of reporting negative feedback about health care experiences is a common concern because patients who do not have good experiences with their health care system or medical providers are less likely to respond to a survey administered directly by their health care institution that provided them the care [13]. On social media platforms like Twitter, users may feel unhindered in posting content and therefore share their authentic narratives and perspectives, such as their interactions with health care services, which may be especially important in the context of experiences among racial and ethnic minorities [51]. For instance, Black Twitter users have used Twitter to foster a community network to generate public conversation about their experiences. In particular, they highlight inequities and discrimination they face [51], which can include interactions with health care services. Results from our study may overlap with this community network of Black 
Twitter users, whereby more negative reporting of patient experiences was observed among Black users compared with White users.

\section{The Affordable Care Act and Patient Experiences Across Race and Ethnicity}

From 2013 to 2016, tweets about patient experience declined in negative sentiment across all racial and ethnic groups. This may suggest that users experienced fewer negative experiences in health care during this time. Twitter users who identified as Hispanic/Latino experienced a 1.5 times greater decline in negative sentiment in our study than White Twitter users, a change that may be attributed to improvements in care delivery and potentially increased access and insurance coverage within this population group between the years of 2013 and 2016. The Patient Protection and Affordable Care Act's major provisions came into effect in 2014, and they specifically aimed to expand the quality of care and public health coverage for racial and ethnic minorities [52,53], who historically have been less likely to receive quality care and insurance compared with White patients. As a result of the implementation of the ACA, racial and ethnic minorities showed the largest gains in health insurance coverage [54-58]. From 2013 to 2016, a report from the Kaiser Family Foundation showed that Hispanic/Latino patients experienced the greatest decrease in uninsured rates compared with any other racial or ethnic group [58]. Greater insurance coverage among Hispanic/Latino patients may have led to improvement in patient experiences within this group. While it is difficult to draw conclusions from the findings in our study, it is promising that the greatest increases in patient experience sentiment on Twitter from 2013 to 2016 were observed among Hispanic/Latino patients, which parallels the reports of changing insurance coverage during this period. The Kaiser report also reported that Black and Asian/Pacific Islander patients experienced a reduction in uninsured rates, but this change was not as great as the change experienced among Hispanic/Latino patients [58].

Regression results showed that patient experience sentiment increased postimplementation of the ACA's full provisions (2014-2016) compared with preimplementation of the ACA (2013). While our yearly regression model identified that the highest change in sentiment by year was among Hispanic/Latino patients, Twitter users who identified as Black appeared to show the most improvement in patient experience in postimplementation compared with preimplementation of the ACA's full provisions. This change in sentiment among Black Twitter users was 2.2 times greater than the change among White Twitter users. Our results are consistent with the 2016 National Healthcare Quality and Disparities Report from the Agency for Healthcare Research and Quality, which reported a narrowing of racial and ethnic disparities in care in 2014 $[59,60]$. In this report, it was documented that uninsured people received worse care, but after the implementation of the Affordable Care Act's full provisions in 2014, there was an expansion of health coverage, especially among Black and Hispanic patients $[1,59,61]$. This decrease in the percentage of uninsured patients within these populations appears consistent with the rise in patient experience sentiment observed in our study following the full implementation of the ACA in 2014.

\section{Limitations}

Several limitations exist in our study. Certain populations may be excluded, which reduces the external validity of our results. Previous studies have indicated that a higher proportion of Twitter users are located in urban areas compared with rural areas, which may introduce further biases [62]. Additionally, when compared with the general population, Twitter is overrepresented by a younger population group aged 18 to 29 years $[63,64]$, people who live in urban areas [43], and racial and ethnic minority groups [65]. On the other hand, specifically for this patient experience study, this sampling bias may have been beneficial for studying underrepresented minority populations [66,67]. Many disadvantaged groups have been shown to use social media and the internet to access health information, potentially as a means for overcoming their lack of access to adequate health care and health information $[68,69]$. For instance, Twitter has been used to document lesbian, gay, bisexual, transgender, and queer (LGBTQ) disparities in experience because of the higher representation of LGBTQ persons on Twitter compared with traditional surveys [31,32]. Our study used a nontraditional data set of free-forming discussions from Twitter that may capture a more authentic and truthful account of patient experiences than existing restricted hospital-based surveys, which are known to have issues of response and social desirability bias, especially among minority racial and ethnic groups [13].

We used a name-based classification system to identify race and ethnicity in this study. Therefore, our study may be limited, as this method may not have been able to fully capture race. For instance, names that could not be identified with a particular race or ethnicity using this classifier were excluded, and there is also the possibility that some names were identified incorrectly as the wrong race [39]. Additionally, name changes by marriage or for other legal reasons could not be accounted for with this system of classification. Furthermore, this name-based classification is based on preconceived race and ethnic group classifications defined by previous survey data from the United States Census Bureau's 2010 Decennial Census. Thus, this classifier measured race and ethnicity as a single variable, which restricts the ability to depict the multifaceted nature or the complex heterogeneity found within each racial and ethnic group [70]. Lastly, our study revealed important trends in the changes in sentiment of patient experience tweets among racial and ethnic minority groups, and these paralleled similar trends related to increasing insurance coverage and access to care among minority groups following the implementation of the full provisions of the ACA in 2014. It is promising that our findings from Twitter appear consistent with these real-world changes, though it is important to recognize that our study cannot reveal whether changing conversations on Twitter are the direct result of the widespread health policy changes.

\section{Conclusion}

Social media platforms like Twitter may provide a novel method of capturing patient experiences of racial and ethnic minority populations beyond traditional surveys. Based on our study findings on Twitter, disparities in sentiment of patient experience 
across race and ethnicity appear to have declined from 2014 to 2016, which parallels similar positive changes in health care services for minority groups following the implementation of the ACA's full provisions in 2014. Continuing to monitor these patient experiences across diverse racial and ethnic groups on Twitter could be used to explore the long-term impacts of broader changes in health policies, such as the Affordable Care Act, to ensure that these disparities continue to shrink over time.
Health care administrators, providers, and policy makers should consider the potential use of social media data as a method for augmenting existing measurement approaches and data sources for better understanding of patient experiences among underrepresented groups. These are particularly important steps that could inform efforts to improve the quality of care delivery among marginalized racial and ethnic minority groups.

\section{Conflicts of Interest}

None declared.

\section{References}

1. Purnell TS, Calhoun EA, Golden SH, Halladay JR, Krok-Schoen JL, Appelhans BM, et al. Achieving Health Equity: Closing The Gaps In Health Care Disparities, Interventions, And Research. Health Aff (Millwood) 2016 Aug 01;35(8):1410-1415. [doi: 10.1377/hlthaff.2016.0158] [Medline: 27503965]

2. Saha S, Arbelaez JJ, Cooper LA. Patient-physician relationships and racial disparities in the quality of health care. Am $\mathbf{J}$ Public Health 2003 Oct;93(10):1713-1719. [doi: 10.2105/ajph.93.10.1713] [Medline: 14534227]

3. Krieger N, Waterman PD, Chen JT, Soobader M, Subramanian S. Monitoring socioeconomic inequalities in sexually transmitted infections, tuberculosis, and violence: geocoding and choice of area-based socioeconomic measures-the public health disparities Geocoding Project (US). Public Health Reports 2003 May;118(3):240-260. [doi: 10.1016/s0033-3549(04)50245-5]

4. Bailey ZD, Krieger N, Agénor M, Graves J, Linos N, Bassett MT. Structural racism and health inequities in the USA: evidence and interventions. The Lancet 2017 Apr;389(10077):1453-1463. [doi: 10.1016/s0140-6736(17)30569-x]

5. George S, Duran N, Norris K. A Systematic Review of Barriers and Facilitators to Minority Research Participation Among African Americans, Latinos, Asian Americans, and Pacific Islanders. Am J Public Health 2014 Feb;104(2):e16-e31. [doi: 10.2105/ajph.2013.301706]

6. Giordano LA, Elliott MN, Goldstein E, Lehrman WG, Spencer PA. Development, implementation, and public reporting of the HCAHPS survey. Med Care Res Rev 2010 Feb;67(1):27-37. [doi: 10.1177/1077558709341065] [Medline: 19638641]

7. Goldstein E, Elliott MN, Lehrman WG, Hambarsoomian K, Giordano LA. Racial/ethnic differences in patients' perceptions of inpatient care using the HCAHPS survey. Med Care Res Rev 2010 Feb;67(1):74-92. [doi: 10.1177/1077558709341066] [Medline: 19652150$]$

8. Elliott MN, Lehrman WG, Goldstein E, Hambarsoomian K, Beckett MK, Giordano LA. Do hospitals rank differently on HCAHPS for different patient subgroups? Med Care Res Rev 2010 Feb;67(1):56-73. [doi: 10.1177/1077558709339066] [Medline: 19605621$]$

9. Lasek RJ, Barkley W, Harper DL, Rosenthal GE. An evaluation of the impact of nonresponse bias on patient satisfaction surveys. Med Care 1997 Jun;35(6):646-652. [doi: 10.1097/00005650-199706000-00009] [Medline: 9191708]

10. Burroughs TE, Waterman BM, Gilin D, Adams D, McCollegan J, Cira J. Do On-Site Patient Satisfaction Surveys Bias Results? The Joint Commission Journal on Quality and Patient Safety 2005 Mar;31(3):158-166. [doi: 10.1016/s1553-7250(05)31021-x]

11. Perneger TV, Chamot E, Bovier PA. Nonresponse bias in a survey of patient perceptions of hospital care. Med Care 2005 Apr;43(4):374-380. [doi: 10.1097/01.mlr.0000156856.36901.40] [Medline: 15778640]

12. Richman WL, Kiesler S, Weisband S, Drasgow F. A meta-analytic study of social desirability distortion in computer-administered questionnaires, traditional questionnaires, and interviews. Journal of Applied Psychology 1999 Oct;84(5):754-775. [doi: 10.1037/0021-9010.84.5.754]

13. Mazor KM, Clauser BE, Field T, Yood RA, Gurwitz JH. A demonstration of the impact of response bias on the results of patient satisfaction surveys. Health Serv Res 2002 Oct;37(5):1403-1417 [FREE Full text] [doi: 10.1111/1475-6773.11194] [Medline: 12479503]

14. van Ryn M, Fu SS. Paved with good intentions: do public health and human service providers contribute to racial/ethnic disparities in health? Am J Public Health 2003 Feb;93(2):248-255. [doi: 10.2105/ajph.93.2.248] [Medline: 12554578]

15. Greenfield S, Kaplan SH, Kahn R, Ninomiya J, Griffith JL. Profiling care provided by different groups of physicians: effects of patient case-mix (bias) and physician-level clustering on quality assessment results. Ann Intern Med 2002 Jan 15;136(2):111-121. [doi: 10.7326/0003-4819-136-2-200201150-00008] [Medline: 11790062]

16. Saunders CL, Elliott MN, Lyratzopoulos G, Abel GA. Do Differential Response Rates to Patient Surveys Between Organizations Lead to Unfair Performance Comparisons? Medical Care 2016;54(1):45-54. [doi: 10.1097/mlr.0000000000000457]

17. Huynh KP, Jacho-Chávez DT, Tripathi G. The econometrics of complex survey data: Theory and applications. Bingley, United Kingdom: Emerald Group Publishing; 2019. 
18. The Patient Protection and Affordable Care Act. 2010. URL: https://www.govinfo.gov/content/pkg/PLAW-111publ148/ pdf/PLAW-111publ148.pdf [accessed 2020-08-09]

19. Rosenbaum S. The Patient Protection and Affordable Care Act: implications for public health policy and practice. Public Health Rep 2011;126(1):130-135 [FREE Full text] [doi: 10.1177/003335491112600118] [Medline: 21337939]

20. Federal Subsidies for Health Insurance Coverage for People Under Age 65: 2016 to 2026.: Congressional Budget Office; 2016. URL: https://www.cbo.gov/sites/default/files/114th-congress-2015-2016/reports/51385-healthinsurancebaseline.pdf [accessed 2020-08-11]

21. Millenson M, Marci J. Will the Affordable Care Act move patient-centeredness to center stage? Urban Institute 2012 Mar:1-10. [doi: 10.1037/e552122012-001]

22. Epstein RM, Fiscella K, Lesser CS, Stange KC. Why the nation needs a policy push on patient-centered health care. Health Aff (Millwood) 2010 Aug;29(8):1489-1495. [doi: 10.1377/hlthaff.2009.0888] [Medline: 20679652]

23. Clement J. Number of monthly active Twitter users worldwide from 1st quarter 2010 to 1st quarter 2019.: Statistica; 2019 Aug 14. URL: https://www.statista.com/statistics/282087/number-of-monthly-active-twitter-users/ [accessed 2017-04-16]

24. Twitter by the Numbers: Stats, Demographics \& Fun Facts.: OmniCore Agency URL: https://www.omnicoreagency.com/ twitter-statistics/ [accessed 2018-02-23]

25. Crannell WC, Clark E, Jones C, James TA, Moore J. A pattern-matched Twitter analysis of US cancer-patient sentiments. J Surg Res 2016 Dec;206(2):536-542. [doi: 10.1016/j.jss.2016.06.050] [Medline: 27523257]

26. Hswen Y, Naslund JA, Brownstein JS, Hawkins JB. Monitoring Online Discussions About Suicide Among Twitter Users With Schizophrenia: Exploratory Study. JMIR Ment Health 2018 Dec 13;5(4):e11483 [FREE Full text] [doi: 10.2196/11483] [Medline: $\underline{30545811]}$

27. Hswen Y, Naslund JA, Brownstein JS, Hawkins JB. Online Communication about Depression and Anxiety among Twitter Users with Schizophrenia: Preliminary Findings to Inform a Digital Phenotype Using Social Media. Psychiatr Q 2018 Sep;89(3):569-580 [FREE Full text] [doi: 10.1007/s11126-017-9559-y] [Medline: 29327218]

28. Hswen Y, Gopaluni A, Brownstein JS, Hawkins JB. Using Twitter to Detect Psychological Characteristics of Self-Identified Persons With Autism Spectrum Disorder: A Feasibility Study. JMIR Mhealth Uhealth 2019 Feb 12;7(2):e12264 [FREE Full text] [doi: 10.2196/12264] [Medline: $\underline{30747718]}$

29. Du J, Xu J, Song H, Tao C. Leveraging machine learning-based approaches to assess human papillomavirus vaccination sentiment trends with Twitter data. BMC Med Inform Decis Mak 2017 Jul 05;17(Suppl 2):69 [FREE Full text] [doi: 10.1186/s12911-017-0469-6] [Medline: 28699569]

30. Hswen Y, Naslund JA, Chandrashekar P, Siegel R, Brownstein JS, Hawkins JB. Exploring online communication about cigarette smoking among Twitter users who self-identify as having schizophrenia. Psychiatry Res 2017 Nov;257:479-484 [FREE Full text] [doi: 10.1016/j.psychres.2017.08.002] [Medline: 28841509]

31. Hswen Y, Sewalk KC, Alsentzer E, Tuli G, Brownstein JS, Hawkins JB. Investigating inequities in hospital care among lesbian, gay, bisexual, and transgender (LGBT) individuals using social media. Soc Sci Med 2018 Oct;215:92-97. [doi: 10.1016/j.socscimed.2018.08.031] [Medline: 30219749]

32. Hswen Y, Zhang A, Sewalk K, Tuli G, Brownstein JS, Hawkins JB. Use of social media to assess the impact of equitable state policies on LGBTQ patient experiences: An exploratory study. Healthc (Amst) 2020 Jun;8(2):100410. [doi: 10.1016/j.hjdsi.2020.100410] [Medline: $\underline{32241681]}$

33. Perrin A. Social Media Usage: 2005-2015.: Pew Research Center URL: https://www.pewresearch.org/internet/2015/10/08/ social-networking-usage-2005-2015/ [accessed 2020-07-24]

34. Duggan M, Brenner J. The demographics of social media users. Pew Research Center's Internet \& American Life Project Washington, DC 2012:1-3.

35. Sewalk KC, Tuli G, Hswen Y, Brownstein JS, Hawkins JB. Using Twitter to Examine Web-Based Patient Experience Sentiments in the United States: Longitudinal Study. J Med Internet Res 2018 Oct 12;20(10):e10043 [FREE Full text] [doi: 10.2196/10043] [Medline: 30314959]

36. Hutto CJ, Gilbert E. A parsimonious rule-based model for sentiment analysis of social media text. Vader 2014:216-225.

37. Gilbert CHE. A parsimonious rule-based model for sentiment analysis of social media text. Vader 2014:216-225.

38. Kralj Novak P, Smailović J, Sluban B, Mozetič I. Sentiment of Emojis. PLoS One 2015;10(12):e0144296 [FREE Full text] [doi: 10.1371/journal.pone.0144296] [Medline: 26641093]

39. Mateos P. A review of name-based ethnicity classification methods and their potential in population studies. Popul Space Place 2007 Jul;13(4):243-263. [doi: 10.1002/psp.457]

40. Piazza A, Rendine S, Zei G, Moroni A, Cavalli-Sforza LL. Migration rates of human populations from surname distributions. Nature 1987;329(6141):714-716. [doi: 10.1038/329714a0] [Medline: 3670373]

41. M'charek A. The Human Genome Diversity Project: an ethnography of scientific practice. Cambridge, UK: Cambridge University Press; 2005:1-208.

42. Comenetz J. Frequently occurring surnames in the 2010 census.: US Census Bureau; 2010. URL: https://www2.census.gov/ topics/genealogy/2010surnames/surnames.pdf [accessed 2020-08-11]

43. Mislove A, Lehmann S, Ahn YY, Onnela JP, Rosenquist JN. Understanding the Demographics of Twitter Users. 2011 Presented at: 5th Annual AAAI Conference on Weblogs and Social Media; July 17-21, 2011; Barcelona, Spain. 
44. Rodriguez HP, von Glahn T, Grembowski DE, Rogers WH, Safran DG. Physician effects on racial and ethnic disparities in patients' experiences of primary care. J Gen Intern Med 2008 Oct;23(10):1666-1672 [FREE Full text] [doi: 10.1007/s11606-008-0732-8] [Medline: 18651194 ]

45. Zhu J, Weingart SN, Ritter GA, Tompkins CP, Garnick DW. Racial/Ethnic Disparities in Patient Experience With Communication in Hospitals. Medical Care 2015;53(5):446-454. [doi: 10.1097/mlr.0000000000000350]

46. Katz RJ. Addressing the health care needs of American Indians and Alaska Natives. Am J Public Health 2004 Jan;94(1):13-14. [doi: 10.2105/ajph.94.1.13] [Medline: 14713686]

47. Moghaddam JF, Momper SL, Fong T. Discrimination and participation in traditional healing for American Indians and Alaska Natives. J Community Health 2013 Dec;38(6):1115-1123. [doi: 10.1007/s10900-013-9721-x] [Medline: 23821254]

48. Sarche M, Spicer P. Poverty and health disparities for American Indian and Alaska Native children: current knowledge and future prospects. Ann N Y Acad Sci 2008;1136:126-136 [FREE Full text] [doi: 10.1196/annals.1425.017] [Medline: $\underline{18579879]}$

49. Jones DS. The Persistence of American Indian Health Disparities. Am J Public Health 2006 Dec;96(12):2122-2134. [doi: 10.2105/ajph.2004.054262]

50. Castor ML, Smyser MS, Taualii MM, Park AN, Lawson SA, Forquera RA. A Nationwide Population-Based Study Identifying Health Disparities Between American Indians/Alaska Natives and the General Populations Living in Select Urban Counties. Am J Public Health 2006 Aug;96(8):1478-1484. [doi: 10.2105/ajph.2004.053942]

51. Clark M. To tweet our own cause: A mixed-methods study of the online phenomenon "Black Twitter". Carolina Digital Repository 2014 Dec:1-174.

52. Sommers BD, Gunja MZ, Finegold K, Musco T. Changes in Self-reported Insurance Coverage, Access to Care, and Health Under the Affordable Care Act. JAMA 2015 Jul 28;314(4):366-374. [doi: 10.1001/jama.2015.8421] [Medline: 26219054]

53. Uberoi N, Finegold K, Gee E. Health insurance coverage and the Affordable Care Act 2010-2016. Washington, DC: Department of Health and Human Services, Office of the Assistant Secretary for Planning and Evaluation; 2010. URL: https://aspe.hhs.gov/system/files/pdf/187551/ACA2010-2016.pdf [accessed 2020-08-11]

54. Lillie-Blanton M, Hoffman C. The role of health insurance coverage in reducing racial/ethnic disparities in health care. Health Aff (Millwood) 2005;24(2):398-408. [doi: 10.1377/hlthaff.24.2.398] [Medline: 15757923]

55. Clemans-Cope L, Kenney GM, Buettgens M, Carroll C, Blavin F. The Affordable Care Act's coverage expansions will reduce differences in uninsurance rates by race and ethnicity. Health Aff (Millwood) 2012 May;31(5):920-930. [doi:

10.1377/hlthaff.2011.1086] [Medline: 22566430]

56. Chen J, Vargas-Bustamante A, Mortensen K, Ortega AN. Racial and Ethnic Disparities in Health Care Access and Utilization Under the Affordable Care Act. Medical Care 2016;54(2):140-146. [doi: 10.1097/mlr.0000000000000467]

57. Artiga S. Health coverage by race and ethnicity: the potential impact of the Affordable Care Act.: Kaiser Family Foundation; 2014. URL: https://www.kff.org/wp-content/uploads/2014/07/8423-health-coverage-by-race-and-ethnicity.pdf [accessed 2020-08-11]

58. Artiga S, Ubri P, Foutz J, Damico A. Health Coverage by Race and Ethnicity: Examining Changes Under the ACA and the Remaining Uninsured.: Kaiser Family Foundation; 2016. URL: http://files.kff.org/attachment/

Issue-Brief-Health-Coverage-by-Race-and-Ethnicity-Examining-Changes-Under-the-ACA-and-the-Remaining-Uninsured [accessed 2020-08-11]

59. Fiscella K, Sanders MR. Racial and Ethnic Disparities in the Quality of Health Care. Annu Rev Public Health 2016;37:375-394. [doi: 10.1146/annurev-publhealth-032315-021439] [Medline: 26789384]

60. Agency for Healthcare Research and Quality. 2016 National Healthcare Quality and Disparities Report. 2016. URL: https:/ /www.ahrq.gov/research/findings/nhqrdr/nhqdr16/index. html\#: :text=The\%20report $\% 20$ is $\% 20$ based $\% 20$ on,health $\% 20$ care $\% 20$ services $\% 20$ and $\% 20$ settings. \&text=The\%20report\%20is\%20produced\%20with,Disparities\%20Report\%20Data\%20and\%20Tools [accessed 2020-08-11]

61. Burstin H, Leatherman S, Goldmann D. The evolution of healthcare quality measurement in the United States. J Intern Med 2016 Feb;279(2):154-159 [FREE Full text] [doi: 10.1111/joim.12471] [Medline: 26785953]

62. Fink C, Bos A, Perrone A, Liu E, Kopecky J. Twitter, Public Opinion, and the 2011 Nigerian Presidential Election. 2011 Presented at: 2013 International Conference on Social Computing (SocialCom); Sep 8-14, 2011; Alexandria, VA p. 311-320. [doi: 10.1109/SocialCom.2013.50]

63. Madden M, Lenhart A, Cortesi A, Gasser U, Duggan M, Smith A, et al. Teens, Social Media, and Privacy.: Pew Research Center; 2013. URL: https://www.pewresearch.org/internet/2013/05/21/teens-social-media-and-privacy/ [accessed 2020-08-11]

64. Social Media Fact Sheet.: Pew Research Center URL: http://www.pewinternet.org/fact-sheet/social-media/ [accessed 2018-11-10]

65. Oktay H, Firat A, Ertem Z. Demographic breakdown of twitter users: An analysis based on names. Academy of Science and Engineering (ASE) 2014:A.

66. Yancey AK, Ortega AN, Kumanyika SK. Effective recruitment and retention of minority research participants. Annu Rev Public Health 2006;27:1-28. [doi: 10.1146/annurev.publhealth.27.021405.102113] [Medline: 16533107] 
67. Wendler D, Kington R, Madans J, Van Wye G, Christ-Schmidt H, Pratt LA, et al. Are racial and ethnic minorities less willing to participate in health research? PLoS Med 2006 Feb;3(2):e19 [FREE Full text] [doi: 10.1371/journal.pmed.0030019] [Medline: 16318411$]$

68. Mesch G, Mano R, Tsamir J. Minority status and health information search: a test of the social diversification hypothesis. Soc Sci Med 2012 Sep;75(5):854-858. [doi: 10.1016/j.socscimed.2012.03.024] [Medline: 22633160]

69. Gayet-Ageron A, Agoritsas T, Schiesari L, Kolly V, Perneger TV. Barriers to participation in a patient satisfaction survey: who are we missing? PLoS One 2011;6(10):e26852 [FREE Full text] [doi: 10.1371/journal.pone.0026852] [Medline: 22046382]

70. Connolly H, Gardener D. Who are the Other ethnic groups Social and welfare reports. Office for National Satistics, London 2006:1-2.

\author{
Abbreviations \\ ACA: Affordable Care Act \\ LGBTQ: lesbian, gay, bisexual, transgender, and queer \\ VADER: Valence Aware Dictionary for Sentiment Reasoner

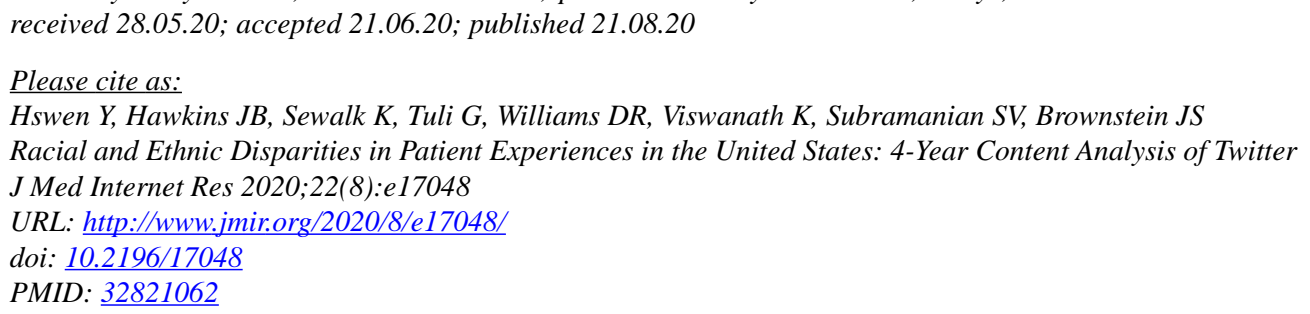

(C)Yulin Hswen, Jared B Hawkins, Kara Sewalk, Gaurav Tuli, David R Williams, K Viswanath, S V Subramanian, John S Brownstein. Originally published in the Journal of Medical Internet Research (http://www.jmir.org), 21.08.2020. This is an open-access article distributed under the terms of the Creative Commons Attribution License (https://creativecommons.org/licenses/by/4.0/), which permits unrestricted use, distribution, and reproduction in any medium, provided the original work, first published in the Journal of Medical Internet Research, is properly cited. The complete bibliographic information, a link to the original publication on http://www.jmir.org/, as well as this copyright and license information must be included. 